\title{
A year in general thoracic surgery published in the Journal of Thoracic and Cardiovascular Surgery: 2020
}

\author{
Michael Lanuti, MD, ${ }^{\mathrm{a}}$ Jules Lin, MD, ${ }^{\mathrm{b}}$ Thomas Ng, MD, ${ }^{\mathrm{c}}$ and Bryan M. Burt, $\mathrm{MD}^{\mathrm{d}}$
}

The challenges and uncertainties of the year 2020 touched humanity. The entire field of medicine paused, united, and confronted a contagion that has redesigned our professional practices and our lives. This was a time when many surgical specialties stopped operating altogether to redirect resources to the many patients with severe acute respiratory syndrome coronavirus 2 , the virus that causes coronavirus disease 2019 (COVID-19). A tireless troop of caregivers, technicians, and innovators, general thoracic surgeons stood on the front line of COVID-19 and cared for the sickest of patients, implementing life-saving and life-sustaining therapies, including extracorporeal membrane oxygenation (ECMO) and tracheostomy. At the same time, we scientifically evaluated the risks of transmission of this virus to our cancer patients and other patients who needed surgical therapies that could not be safely delayed, ${ }^{1}$ and wrote the book on how surgery in these patients should be appropriately handled. $^{2}$ The Journal of Thoracic and Cardiovascular Surgery (Journal) showcased these and our other contributions to the pandemic during 2020. Perhaps even more notable, is the surgical innovation and advancement of our field that persisted during 2020, despite these challenges. Many of these advances were published in the Journal and are highlighted in the following sections.

\section{LUNG}

\section{Lung Cancer: Technique}

Several advancements in minimally invasive lung resection can be found in the 2020 volumes of the Journal. Published in the Journal was a prospective multicenter clinical trial by Liberman and colleagues ${ }^{3}$ that demonstrated safety in dividing pulmonary artery branches $\leq 7 \mathrm{~mm}$ during lobectomy. Remarkably there were only 3 of 239 vessel sealer failures and only 1 conversion to thoracotomy. ${ }^{3}$ A strategy only once imagined, this article and its accompanying video

\footnotetext{
From the a Division of Thoracic, Surgery, Massachusetts General Hospital, Harvard Medical School, Boston, Mass; 'bection of Thoracic Surgery, University of Michigan, Ann Arbor, Mich; ${ }^{\circ}$ Division of Thoracic Surgery, College of Medicine, University of Tennessee Health Science Center, Memphis, Tenn; and ${ }^{\mathrm{d}}$ Division of General Thoracic Surgery, Michael E. DeBakey Department of Surgery, Baylor College of Medicine, Houston, Tex.

Received for publication March 17, 2021; revisions received March 17, 2021; accepted for publication March 19, 2021; available ahead of print April 20, 2021.

Address for reprints: Bryan M. Burt, MD, Division of General Thoracic Surgery, Department of Surgery, Baylor College of Medicine, One Baylor Plaza, MS BCM 390, Houston, TX 77030 (E-mail: bryan.burt@bcm.edu).

J Thorac Cardiovasc Surg 2021;162:253-8

$0022-5223 / \$ 36.00$

Copyright (C) 2021 by The American Association for Thoracic Surgery

https://doi.org/10.1016/j.jtcvs.2021.03.106
}

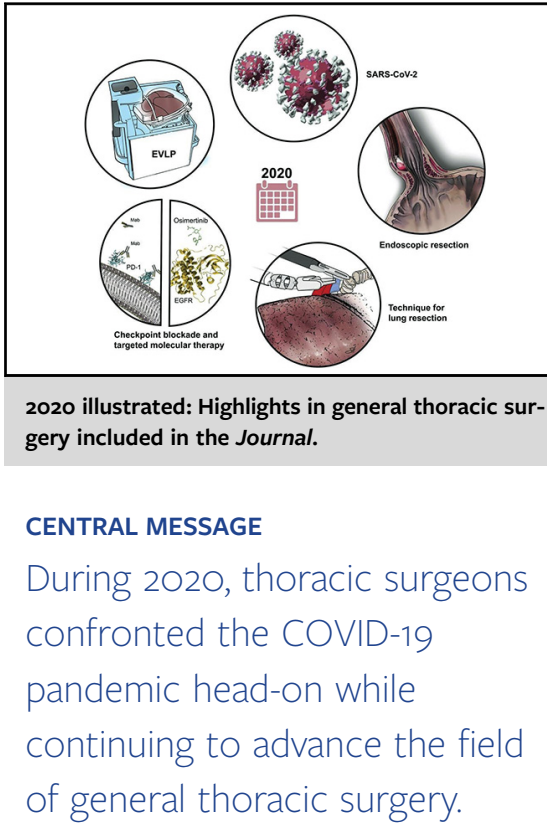

highlight how rigorous surgical investigation can safely usher new surgical technique into practice. Also published in 2020 was an important proceeding by Qiu and colleagues ${ }^{4}$ showcasing the evolution of minimally invasive surgery for complex and extended lung resections. The authors presented a propensity-matched analysis of 188 sleeve lobectomies performed robotically, thoracoscopically, or by thoracotomy. ${ }^{4}$ No difference in 90-day morbidity or mortality was shown among the 3 groups, with no conversions to thoracotomy in the minimally invasive groups. The robotic technique was associated with decreased blood loss, shorter operative time, and earlier chest tube removal. ${ }^{4}$

Comparative efficacy of stereotactic body radiotherapy (SBRT) and surgery in the treatment of patients with nonsmall cell lung cancer (NSCLC) remains a highly visible and opinionated theme in the field of thoracic oncology. Until publication of the forthcoming results of modern randomized comparisons of lobectomy with sublobar resection for NSCLC, lobectomy is considered by most to be the gold standard treatment for early-stage NSCLC and is often the operation compared against SBRT. During 2020, the Journal published a rigorous national cancer database (NCDB) study by $\mathrm{Wu}$ and colleagues ${ }^{5}$ that compared the results of SBRT and other locally invasive ablative strategies 
(eg, thermal ablation) with those of sublobar resection for patients with clinical stage T1 to T2a N0 NSCLC. Propensity-matched analyses demonstrated longer overall survival by sublobar resection that persisted in patients with tumors $\leq 2 \mathrm{~cm} .{ }^{5}$ This study included a large sample size, and its data were informative; however, it investigated a 10-year period (2004-2014) that was relatively early in the evolution of ablative technologies.

\section{Immunotherapy, Targeted Molecular, and Adjuvant Therapy}

The field of thoracic oncology has perhaps never been more exciting. Immune checkpoint inhibitors have become standard of care first-line therapy for most patients with metastatic NSCLC and are being rapidly tested in clinical trials for the treatment of early-stage NSCLC in combination with surgery. Several important gaps in the field of immune checkpoint inhibitors therapy for NSCLC were addressed in 2020 in the Journal, including the management of immune-related adverse events in our surgical populations by Stiles and colleagues ${ }^{6}$ and using transcriptomic signatures to stratify tumors into immunogenic or immuneresistant subtypes to potentially explain the variable response to PD-1 blockade in NSCLC by Jang and colleagues.?

Molecular targeted therapy has revolutionized the treatment of patients with metastatic NSCLC and is first-line therapy for patients with stage IV disease who have targetable mutations in oncogenes such as the epidermal growth factor receptor. The multinational randomized Adjuvant Aura (ADAURA) trial was published toward the close of 2020 and already deeply influences the care of patients with surgically resectable epidermal growth factor receptor-mutated lung adenocarcinomas. The primary end point of the trial was disease-free survival for patients with stage II to IIIA disease receiving adjuvant osimertinib. Hazard ratios (0.17-0.39) were among the lowest ever published for a lung cancer adjuvant treatment, and a strong signal was also shown for patients with stage IB disease. ${ }^{8}$ These exciting data are enhancing the depth of collaboration between medical and surgical thoracic oncology and are actively improving the care of patients with surgically resectable lung adenocarcinomas, particularly in the neoadjuvant space.

Traditional adjuvant therapies remain important in the treatment of patients with surgically resectable NSCLC and several notable studies were published in the Journal during 2020. A large NCDB investigation of node-negative large cell neuroendocrine lung cancers $(n=1770)$ by Wakeam and colleagues ${ }^{9}$ demonstrated that chemotherapy in the adjuvant setting was associated with improved overall survival in patients whose tumors were $>3 \mathrm{~cm}$ in size, that lobectomy was superior to sublobar resection, and that adjuvant radiotherapy did not influence survival. Adjuvant therapy for incompletely resected $(\mathrm{R}+$ ) stage I through IIIA NSCLC was tackled in another large NCDB study by Edwards and colleagues. ${ }^{10}$ The authors showed that NSCLC patients with indeterminate margins (defined as margin-positive resection) who were treated with adjuvant chemotherapy or radiation did not experience a survival benefit compared with those who did not have adjuvant therapy. ${ }^{10}$ These data are expected to inform the $\mathrm{R}$ classification in the next staging proposal by the International Association for the Study of Lung Cancer. ${ }^{11}$

\section{Biology}

In the current era, it is surprising that we are still faced with uncertainty in whether 2 NSCLCs in the same patient represent stage I or stage IV (separate primaries vs metastatic disease). In a study of multifocal NSCLCs published this year in the Journal, Zheng and colleagues ${ }^{12}$ used next generation DNA sequencing of NSCLC tumors with similar histology and were able to improve the distinction between synchronous primary lung cancers and intrapulmonary metastatic disease. We submit that this approach presages the solution to this unsolved problem in thoracic oncology. Pani and colleagues ${ }^{13}$ investigated the biology of small $(\leq 2 \mathrm{~cm})$ NSCLC tumors in 555 patients undergoing surgery. Although tumors $\leq 1 \mathrm{~cm}$ were less likely to have lymph node metastases compared with 1.1 - to $2-\mathrm{cm}$ tumors $(6.8 \%$ vs $13.3 \%)$, the authors demonstrated no correlation to tumor histology (except for the micropapillary subtype of adenocarcinoma) and highlighted the timeless lesson of thorough nodal dissection during lung cancer resection. ${ }^{13}$

\section{ESOPHAGUS}

Excitement in endoscopic resection (ER) for esophageal cancer has maintained momentum into and throughout 2020, and the National Comprehensive Cancer Network recommends ER as the preferred treatment for medically fit patients with T1a esophageal adenocarcinoma or squamous cell carcinoma. ${ }^{14}$ Considering the magnitude of esophagectomy, this recommendation might seem appropriate for elderly patients; however, its application to younger patients must take into account the likelihood of cure by each approach. During 2020, in the Journal, Raman and colleagues ${ }^{15}$ applied multivariable Cox and propensity score matching to a cohort of 831 patients with clinical T1a esophageal cancer and demonstrated that overall survival was similar between ER and esophagectomy, regardless of age. These data provide strong evidence in support of current National Comprehensive Cancer Network guidelines recommending ER as the preferred treatment for all patients with T1a esophageal cancer. Nobel and ${ }^{16}$ colleagues provided other eye-opening data on the relationship between age and esophageal cancer in the 2020 issues of the Journal. The authors evaluated more than 100,000 patients 
with esophageal adenocarcinoma within the NCDB and showed that the frequency of metastatic disease at the time of diagnosis was highest in the youngest age group, irrespective of tumor grade. ${ }^{16}$ Without the need for sophisticated statistical analysis, this simple population study should raise awareness and promote a more aggressive clinical evaluation in younger patients with or at high-risk of developing esophageal adenocarcinoma.

The benefits of immunotherapy are now being realized for patients with esophageal cancer, and during 2020, the results of Randomized Trial of Adjuvant Nivolumab in Resected Esophageal or Gastroesophageal Junction Cancer (CheckMate 577) were presented at the European Society of Medical Oncology Virtual Congress. CheckMate 577 randomized 794 patients to receive nivolumab versus placebo after trimodality (ie, chemotherapy/radiation followed by surgery) therapy for esophageal adenocarcinoma or squamous cell carcinoma and reported a doubling of median disease-free survival, corresponding to a $31 \%$ risk reduction in recurrence or death, in favor of nivolumab. ${ }^{17}$ Continued advancement in checkpoint blockade for esophageal cancer is expected during 2021.

\section{TRANSPLANT}

The number of lung transplants performed in the United States has increased on an annual basis and reached an alltime high of 2759 transplants during 2019. The field has experienced a $62 \%$ increase in lung donors over the past decade, along with a concomitant decrease in wait list mortality and incremental improvements in posttransplant survival. ${ }^{18}$

\section{Ex-Vivo Lung Perfusion}

During 2020, the Journal published a series of investigations that could ultimately expand the available pool of donor lungs, using ex-vivo lung perfusion (EVLP). Tian and colleagues ${ }^{19}$ reported a meta-analysis of 8 studies totaling 1191 patients evaluating outcomes of EVLP on marginal donor lungs. Although EVLP donors had more abnormal radiographs, worse donor arterial oxygen tension/inspired oxygen fraction, and a longer smoking history, there were no significant differences between EVLP and non-EVLP donor lungs in outcomes that included grade 3 primary graft dysfunction and 1-year survival. ${ }^{19}$ In among the largest single-center experiences, Cypel and colleagues ${ }^{20}$ increased their annual lung transplant activity by $70 \%$ using EVLP to assess donor lungs. The authors reported a $70 \%$ utilization rate, ranging from $63 \%$ for high risk donation after cardiac death to $82 \%$ for standard risk donation after cardiac death with maintenance of excellent outcomes. ${ }^{20}$ In addition, techniques and protocols for EVLP are being continuously and rapidly refined based on new and exciting data. In a multicenter study of 110 patients, Leiva-Juárez and colleagues ${ }^{21}$ demonstrated that extended
post-EVLP cold ischemic time ( $>287$ minutes) was associated with an increased risk of primary graft dysfunction and 1 -year mortality. Whereas EVLP has generally been limited to $<24$ hours of support, Hozain and colleagues ${ }^{22}$ reported preclinical results describing their technique to maintain extracorporeal donor lungs using cross-circulation for 4 days in a porcine model, which may lead to innovative strategies to rehabilitate marginal donor lungs.

\section{Extended Criteria Organs}

Another strategy to increase the number of available donor organs is the use of donor lungs from patients with infectious risk factors. In the Journal, Carli and colleagues ${ }^{23}$ evaluated the influence of the US Public Health Service 2013 broadened definition of increased risk donors on lung transplant outcomes. Investigating the period from 2006 to 2017, the authors noted that the proportion of high-risk donors grew from $8 \%$ before 2013 , to $22 \%$ after 2013, with similar graft and patient survival compared with standard risk infectious donors. ${ }^{23}$ Following the publication of a clinical trial in the New England Journal of Medicine on the use of heart and lung transplants from hepatitis C-infected donors to uninfected recipients, ${ }^{24}$ an important invited editorial in the Journal provided expert insight on a strategy of using hepatitis C-infected donor lungs in combination with antiviral agents to expand the pool of donor organs. ${ }^{25}$ This approach has also been supported in a study that stratified all deceased organ donors from 2015 to 2018 by hepatitis C status using Scientific Registry of Transplant Recipients data and estimated that transplanting lungs from hepatitis $\mathrm{C}$ positive donors would lead to an increase of at least 55 donor lungs per year. ${ }^{26}$

\section{Outcomes and Perioperative Management}

In a longitudinal study evaluating outcomes of lung transplantation from 2005 to 2018, Hamilton and colleagues ${ }^{27}$ showed that survival after lung transplantation in mechanically ventilated patients has improved over time, although preoperative mechanical ventilation remains an important risk factor. Ius and colleagues ${ }^{28}$ evaluated the long-term outcomes of 311 lung transplant recipients who required intraoperative ECMO. Although these patients had a higher pretransplant risk profile and a more complicated postoperative course, those who survived to hospital discharge had no difference in 5-year survival or chronic lung allograft dysfunction. ${ }^{28}$ Meanwhile, Hoetzenecker and colleagues ${ }^{29}$ evaluated routine use of intraoperative ECMO in 159 patients undergoing lung transplantation. They reported grade 3 primary graft dysfunction of only $3 \%$ and a 2 -year survival of $86 \%$ and advocate for the routine use of intraoperative ECMO. ${ }^{29}$

To address the problem of postoperative deep venous thrombosis in lung transplantation, Jorge and colleagues ${ }^{30}$ evaluated 1141 patients who received prophylactic 
subcutaneous heparin postoperatively and demonstrated a decline in the rate of deep venous thrombosis from $17.3 \%$ to $8.8 \%$ after a universal screening program was implemented. Two publications in the Journal in 2020 evaluated the association of gastroesophageal reflux and outcomes after lung transplantation. Davidson and colleagues ${ }^{31}$ performed a meta-analysis of 6 retrospective studies and showed that antireflux surgery resulted in a small increase in forced expiratory volume in 1 second (FEV1) in lung transplant patients, but a large effect of antireflux surgery on the rate of FEV1 change, suggesting meaningful benefit of antireflux surgery in patients with a declining FEV1. ${ }^{30}$ Meanwhile, esophageal aperistalsis is believed to increase the risk of allograft dysfunction due to reflux and aspiration from poor esophageal clearance. In their evaluation of 31 patients undergoing lung transplantation who have esophageal aperistalsis, Masuda and colleagues ${ }^{32}$ found that 1-, 3-, and 5-year survival was worse in patients with aperistalsis and that the 19 patients with improvement in esophageal motility on manometry posttransplant had a similar survival to the control group. This series of articles are expected to inform the refinement of perioperative protocols for patients undergoing lung transplantation.

\section{PLEURA}

Malignant pleural mesothelioma (MPM) has largely defeated traditional systemic therapies; however, in early 2021, results of the CheckMate 743 trial were published in the Lancet $^{33}$ and might improve outcomes of first-line therapy for individuals with MPM. This randomized, phase 3 trial demonstrated improved overall survival of first-line combination immunotherapy (nivolumab plus ipilimumab) compared with standard platinum plus pemetrexed chemotherapy for patients with unresectable, previously untreated mesothelioma. In a relevant study published in the Journal, DePerrot and colleagues ${ }^{34}$ showed importance of the tumor immune microenvironment of MPM, particularly of its CD8 T-cell compartment, in response to hypofractionated hemithoracic radiation before surgery. Similar to the personalized strategies that benefit patients with NSCLC, targeted molecular therapy holds promise in MPM but first requires a thorough understanding of its tumor genomics. The molecular landscape of this unique tumor has been unraveled over the past several years and is featured in an invited article by Bueno and colleagues ${ }^{35}$ this year in the Journal.

\section{MEDIASTINUM}

In a national analysis, Yang and colleagues ${ }^{36}$ demonstrated shorter length of stay following minimally invasive thymectomy for stage I through III thymoma, compared with open thymectomy, without increased rates of margin positivity, perioperative morbidity, or decreases in overall survival. Kim and colleagues $^{37}$ performed a useful systematic analysis of the paraneoplastic syndromes associated with thymoma and showed that a multimodal treatment approach that includes resection is able to achieve remission of the paraneoplastic syndrome in the majority $(76 \%)$ of patients, which is associated with improved overall survival.

\section{TRACHEA}

During 2020 in the Journal, an important, humbling report in the field of tracheal replacement was published. In this proceeding, the authors analyzed 3 patients who received synthetic tracheal grafts seeded with autologous bone marrow mononuclear cells and showed that these grafts did not become living functional grafts and lead to debilitating complications and death. ${ }^{38}$ The publication of these sobering data are considered an important milestone in recalibrating investigational approaches to tracheal replacement in humans.

\section{CONCLUSIONS}

Despite the exceptional challenges and uncertainties that we, our patients, and our families have faced this past year from the global COVID-19 pandemic, thoracic surgeons have continued to provide essential care to our patients, including those with lung and esophageal cancer and endstage lung disease. Our specialty not only continues to thrive, but driven by surgeon innovators, educators, and researchers, our persistence has continued to drive the advancement of our field during 2020.

\section{Conflict of Interest Statement}

The authors reported no conflicts of interest.

The Journal policy requires editors and reviewers to disclose conflicts of interest and to decline handling or reviewing manuscripts for which they may have a conflict of interest. The editors and reviewers of this article have no conflicts of interest.

\section{References}

1. Peng S, Huang L, Zhao B, Zhou S, Braithwaite I, Zhang N, et al. Clinical course of coronavirus disease 2019 in 11 patients after thoracic surgery and challenges in diagnosis. J Thorac Cardiovasc Surg. 2020;160:585-92.e2.

2. Thoracic Surgery Outcomes Research Network I, Antonoff M, Backhus L, Boffa DJ, Broderick SR, Brown LM, et al. COVID-19 guidance for triage of operations for thoracic malignancies: a consensus statement from Thoracic Surgery Outcomes Research Network. J Thorac Cardiovasc Surg. 2020;160:601-5.

3. Liberman M, Goudie E, Morse C, Hanna W, Evans N, Yasufuku K, et al. Prospective, multicenter, international phase 2 trial evaluating ultrasonic energy for pulmonary artery branch sealing in video-assisted thoracoscopic surgery lobectomy. J Thorac Cardiovasc Surg. September 30, 2019 [Epub ahead of print].

4. Qiu T, Zhao Y, Xuan Y, Qin Y, Niu Z, Shen Y, et al. Robotic sleeve lobectomy for centrally located non-small cell lung cancer: a propensity score-weighted comparison with thoracoscopic and open surgery. J Thorac Cardiovasc Surg. 2020; 160:838-46.e2.

5. Wu J, Bai HX, Chan L, Su C, Zhang PJ, Yang L, et al. Sublobar resection compared with stereotactic body radiation therapy and ablation for early stage 
non-small cell lung cancer: a National Cancer Database study. J Thorac Cardiovasc Surg. 2020;160:1350-7.e11.

6. Stiles BM, Sepesi B, Broderick SR, Bott MJ. Perioperative considerations for neoadjuvant immunotherapy in non-small cell lung cancer. J Thorac Cardiovasc Surg. 2020;160:1376-82.

7. Jang HJ, Lee HS, Ramos D, Park IK, Kang CH, Burt BM, et al. Transcriptomebased molecular subtyping of non-small cell lung cancer may predict response to immune checkpoint inhibitors. J Thorac Cardiovasc Surg. 2020;159: 1598-610.e3.

8. Wu YL, Tsuboi M, He J, John T, Grohe C, Majem M, et al. Osimertinib in resected EGFR-mutated non-small-cell lung cancer. N Engl J Med. 2020;383: 1711-23.

9. Wakeam E, Adibfar A, Stokes S, Leighl NB, Giuliani ME, Varghese TK Jr, et al. Defining the role of adjuvant therapy for early-stage large cell neuroendocrine carcinoma. J Thorac Cardiovasc Surg. 2020;159:2043-454.e9.

10. Raman V, Jawitz OK, Yang CJ, Voigt SL, Kim AW, Tong BC, et al. The influence of adjuvant therapy on survival in patients with indeterminate margins following surgery for non-small cell lung cancer. J Thorac Cardiovasc Surg. 2020;159: 2030-340.e4.

11. Edwards JG, Chansky K, Van Schil P, Nicholson AG, Boubia S, Brambilla E, et al. The IASLC Lung Cancer Staging Project: analysis of resection margin status and proposals for residual tumor descriptors for non-small cell lung cancer. J Thorac Oncol. 2020;15:344-59.

12. Zheng R, Shen Q, Mardekian S, Solomides C, Wang ZX, Evans NR 3rd. Molecular profiling of key driver genes improves staging accuracy in multifocal nonsmall cell lung cancer. J Thorac Cardiovasc Surg. 2020;160:e71-9.

13. Pani E, Kennedy G, Zheng X, Ukert B, Jarrar D, Gaughan C, et al. Factors associated with nodal metastasis in 2-centimeter or less non-small cell lung cancer. $J$ Thorac Cardiovasc Surg. 2020;159:1088-896.e1.

14. National Comprehensive Cancer Network (NCCN). Esophageal and esophagogastric junction cancers (Version 1.2021). Available at: https://www.ncen.org/ professionals/physician_gls/pdf/esophageal.pdf. Accessed February 12, 2021.

15. Raman V, Jawitz OK, Voigt SL, Yang CJ, Harpole DH, D’Amico TA, et al. The effect of age on survival after endoscopic resection versus surgery for T1a esophageal cancer. J Thorac Cardiovasc Surg. 2020;160:295-302.e3.

16. Nobel TB, Curry M, Gennarelli R, Jones DR, Molena D. Higher clinical suspicion is needed for prompt diagnosis of esophageal adenocarcinoma in young patients. J Thorac Cardiovasc Surg. April 16, 2019 [Epub ahed of print].

17. Kelly RJ, Ajani JA, Kuzdzal J, Zander T, Van Cutsem E, Piessen G, et al. LBA9 PR Adjuvant nivolumab in resected esophageal or gastroesophageal junction cancer (EC/GEJC) following neoadjuvant chemoradiation therapy (CRT): first results of the CheckMate 577 study. Ann Oncol. 2020;31:s1193-4.

18. Valapour M, Lehr CJ, Skeans MA, Smith JM, Miller E, Goff R, et al. OPTN/ SRTR 2019 Annual data report: lung. Am J Transplant. 2021;21(Suppl 2): 441-520.

19. Tian D, Wang Y, Shiiya H, Sun CB, Uemura Y, Sato M, et al. Outcomes of marginal donors for lung transplantation after ex vivo lung perfusion: a systematic review and meta-analysis. J Thorac Cardiovasc Surg. 2020;159:720-30.e6.

20. Cypel M, Yeung JC, Donahoe L, Chen M, Zamel R, Hoetzenecker K, et al. Normothermic ex vivo lung perfusion: does the indication impact organ utilization and patient outcomes after transplantation? J Thorac Cardiovasc Surg. September 9, 2019 [Epub ahead of print].

21. Leiva-Juarez MM, Urso A, Arango Tomas E, Lederer DJ, Sanchez P, Griffith B, et al. Extended post-ex vivo lung perfusion cold preservation predicts primary graft dysfunction and mortality: results from a multicentric study. J Heart Lung Transplant. 2020;39:954-61.

22. Hozain AE, Tipograf Y, Pinezich MR, Cunningham KM, Donocoff R, Queen D, et al. Multiday maintenance of extracorporeal lungs using cross-circulation with conscious swine. J Thorac Cardiovasc Surg. 2020;159:1640-53.e18.
23. Lehr CJ, Lopez R, Arrigain S, Schold J, Koval C, Valapour M. The impact of change in definition of increased-risk donors on survival after lung transplant J Thorac Cardiovasc Surg. 2020;160:572-81.

24. Woolley AE, Singh SK, Goldberg HJ, Mallidi HR, Givertz MM, Mehra MR, et al Heart and Lung Transplants from HCV-infected donors to uninfected recipients. N Engl J Med. 2019;380:1606-17.

25. Van Raemdonck D, Nevens F, Van Cleemput J, Vos R, Neyrinck A, Verleden GM. Fishing in the thoracic organ donor pool: what next if the catch of the day got infected with hepatitis C virus? J Thorac Cardiovasc Surg. 2020; 159:2121-5.

26. Mooney JJ, Purington N, Mohabir P, Dhillon GS. Estimated impact of hepatitis C-positive lung donor utilization on US donor lung supply. Am J Transplant. 2020;20:289-97.

27. Hamilton BCS, Dincheva GR, Matthay MA, Hays S, Singer JP, Brzezinski M, et al. Improved survival after lung transplantation for adults requiring preoperative invasive mechanical ventilation: a national cohort study. J Thorac Cardiovasc Surg. 2020;160:1385-895.e6.

28. Ius F, Aburahma K, Boethig D, Salman J, Sommer W, Draeger H, et al. Longterm outcomes after intraoperative extracorporeal membrane oxygenation during lung transplantation. J Heart Lung Transplant. 2020;39:915-25.

29. Hoetzenecker K, Benazzo A, Stork T, Sinn K, Schwarz S, Schweiger T, et al Bilateral lung transplantation on intraoperative extracorporeal membrane oxygenator: an observational study. J Thorac Cardiovasc Surg. 2020;160: 320-7.e1.

30. Jorge A, Sanchez PG, Hayanga JWA, Pilewski JM, Morrell M, Tuft M, et al Routine deep vein thrombosis screening after lung transplantation: incidence and risk factors. J Thorac Cardiovasc Surg. 2020;159:1142-50.

31. Davidson JR, Franklin D, Kumar S, Mohammadi B, Dawas K, Eaton S, et al. Fundoplication to preserve allograft function after lung transplant: systematic review and meta-analysis. J Thorac Cardiovasc Surg. 2020;160:858-66.

32. Masuda T, Mittal SK, Csucska M, Kovacs B, Walia R, Huang JL, et al. Esophageal aperistalsis and lung transplant: recovery of peristalsis after transplant is associated with improved long-term outcomes. J Thorac Cardiovasc Surg. 2020;160:1613-26

33. Baas P, Scherpereel A, Nowak AK, Fujimoto N, Peters S, Tsao AS, et al. Firstline nivolumab plus ipilimumab in unresectable malignant pleural mesothelioma (CheckMate 743): a multicentre, randomised, open-label, phase 3 trial. Lancet 2021:397:375-86.

34. de Perrot M, Wu L, Cabanero M, Perentes JY, McKee TD, Donahoe L, et al. Prog nostic influence of tumor microenvironment after hypofractionated radiation and surgery for mesothelioma. J Thorac Cardiovasc Surg. 2020;159:2082-91.e1.

35. Severson DT, De Rienzo A, Bueno R. Mesothelioma in the age of "Omics" before and after the cancer genome atlas. J Thorac Cardiovasc Surg. 2020; 160:1078-83.e2.

36. Yang CJ, Hurd J, Shah SA, Liou D, Wang H, Backhus LM, et al. A national analysis of open versus minimally invasive thymectomy for stage I to III thymoma. $J$ Thorac Cardiovasc Surg. 2020;160:555-67.e15.

37. Zhao J, Bhatnagar V, Ding L, Atay SM, David EA, McFadden PM, et al. A systematic review of paraneoplastic syndromes associated with thymoma: treatment modalities, recurrence, and outcomes in resected cases. J Thorac Cardiovasc Surg. 2020;160:306-14.e14.

38. Fux T, Osterholm C, Themudo R, Simonson O, Grinnemo KH, Corbascio M Synthetic tracheal grafts seeded with bone marrow cells fail to generate functional tracheae: first long-term follow-up study. J Thorac Cardiovasc Surg. 2020; 159:2525-37.e23.

Key words: non-small cell lung cancer, esophageal cancer, lung transplantation, mesothelioma, thymoma 


\section{A Year in General Thoracic Surgery at JTCVS: Recent Articles from AATS Journals}
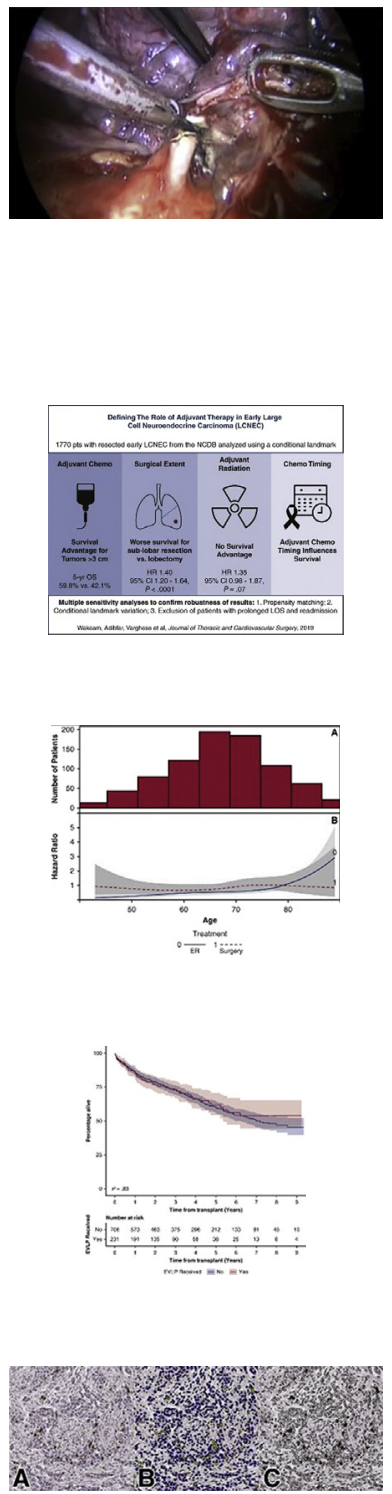

JTCVS: Prognostic influence of tumor microenvironment after hypofractionated radiation and surgery for mesothelioma. de Perrot M, Wu L, Cabanero M, Perentes JY, McKee TD, Donahoe L, Bradbury P, Kohno M, Chan ML, Murakami J, Keshavjee S, Tsao MS, Cho BCJ. J Thorac Cardiovasc Surg. 2020;159(5):2082-2091.

Commentary: A journey of a thousand miles begins with a single step. Chen-Yoshikawa TF. J Thorac Cardiovasc Surg. 2020;159(5):2092-2093.

Commentary: Not only SMART clinically, but translationally! Pass HI. J Thorac Cardiovasc Surg. 2020;159(5):2094-2095. 